\title{
Positional down beating nystagmus in 50 patients: cerebellar disorders and possible anterior semicircular canalithiasis
}

\author{
P Bertholon, A M Bronstein, R A Davies, P Rudge, K V Thilo
}

J Neurol Neurosurg Psychiatry 2002;72:366-372

See end of article for authors' affiliations

\section{Correspondence to:}

Correspondence to:
Professor A M Bronstein Academic Department of Neuro-otology, Division of Neuroscience and Psychological Medicine, Imperial College, Charing

Cross Hospital, Fulham

Palace Road, London, W6 8RF, UK;

A.Bronstein@ic.ac.uk

Received 16 July 2001

In revised form

12 October 2001

Accepted

31 October 2001 onal down beat nystagmus (pDBN).

Objectives: To clarify the clinical significance of positional down beat nystagmus (pDBN).

Results: In 38 patients there was evidence of CNS disease (central group) but in 12 there was not (idiopathic group). In the CNS group, presenting symptoms were gait, speech, and autonomic dysfunction whereas in the idiopathic group patients mostly reported positional vertigo. The main neurological and oculomotor signs in the CNS group were explained by cerebellar dysfunction, including 13 patients with multiple system atrophy. In patients with multiple system atrophy with a prominent extrapyramidal component, the presence of pDBN was helpful in the differential diagnosis of atypical parkinsonism. No patient with pDBN had the Arnold-Chiari malformation, a common cause of constant down beat nystagmus (DBN). In the idiopathic group, the pDBN had characteristics which suggested a peripheral labyrinthine disorder: vertigo, adaptation, and habituation. In six patients an additional torsional component was found (concurrently with the pDBN in three). Features unusual for peripheral disorder were: bilateral positive Dix-Hallpike manoeuvre in nine of 12 patients and selective provocation by the straight head-hanging manoeuvre in two

Conclusion: It is argued that some patients with idiopathic pDBN have benign paroxysmal positional vertigo (BPPV) with lithiasis of the anterior canal. The torsional component may be weak, because of the predominantly sagittal orientation of the anterior canal, and may not be readily seen clinically. Nystagmus provocation by bilateral Dix-Hallpike and straight head-hanging may be explained by the vertical upwards orientation of the ampullary segment of the anterior canal in the normal upright head position. Such orientation makes right-left specificity with the Dix-Hallpike manoeuvre less important than for posterior canal BPPV. This orientation requires a further downwards movement of the head, often achieved with the straight head-hanging position, to provoke migration of the canaliths. The straight head-hanging manoeuvre should be carried out in all patients with a history of positional vertigo and a negative Dix-Hallpike manoeuvre.
$\mathrm{D}$ own beat nystagmus (DBN) in primary gaze is a sign of CNS dysfunction..$^{1-5}$ Occasionally, positional down beat nystagmus (pDBN) is seen in patients without primary gaze DBN. In such cases, a central disorder is the likely explanation but this issue has not been specifically addressed in the literature. However, investigation of these patients does not always disclose a CNS abnormality and there is considerable doubt as to the cause of such pDBN. We review 50 consecutive patients seen between 1984 and 1998 with pDBN; 75\% had clear evidence of CNS dysfunction but in 25\% there was no such abnormality. We discuss the different CNS disorders producing pDBN and examine whether peripheral vestibular disease-namely, lithiasis of the anterior semicircular canalcould also cause it.

\section{MATERIAL AND METHODS}

The patients were referred for a neuro-otological opinion because of one or more of the following problems: vertigo, dizziness, postural instability, or eye movement disorder. All patients in whom pDBN was seen on the Dix-Hallpike manoeuvre, ${ }^{6}$ or when the head was extended directly backwards from the sitting to the supine straight head hanging position were included. The nystagmus was detected by direct clinical observation with the patient's eyes in primary gaze fixating on the examiner's face. Patients with torsional or horizontal nystagmic components added to their pDBN were included. By convention, a left torsional nystagmus means that the upper pole of the eye beats to the patient's left shoulder. Patients with DBN in any position of gaze while upright were excluded.

All patients underwent a neurological, eye movement, and neuro-otological examination. Bithermal caloric testing, as described in Fitzgerald and Hallpike ${ }^{7}$ and complemented with Frenzel's glasses observation, was obtained in 35 patients. Direct current horizontal electro-oculography was conducted in 47 patients and included search for spontaneous/gaze evoked nystagmus, smooth pursuit, optokinetic and rotational testing and, when required, saccadic velocities. Techniques and normal data have been reported elsewhere. ${ }^{8-13}$ As the clinical and instrumental examination of the oculomotor and vestibular system were in agreement the results are combined. Neuroimaging was available according to clinical needs; cranial MRI in 30 patients and CT in 16 patients. Four patients were re-examined to obtain computerised three dimensional video-oculography (SMI, Berlin; bandwith $50 \mathrm{~Hz}$ ) during positional testing.

\section{RESULTS}

The 50 patients were divided into two groups: those with unequivocal CNS dysfunction (38 patients; mean age 51,

Abbreviations: $\mathrm{pDBN}$, positional down beat nystagmus; BPPV, benign paroxysmal positional vertigo; $A C, P C, H C$, ampullary segment of the anterior, posterior, and horizontal semicircular canal 
Table 1 Clinical summary of patients with positional down beat nystagmus and no CNS disease*

\begin{tabular}{|c|c|c|c|c|c|c|c|c|}
\hline \multicolumn{3}{|c|}{ Patient } & \multirow[b]{2}{*}{ Symptom (history) } & \multicolumn{3}{|l|}{ Positional findings } & \multirow[b]{2}{*}{$\begin{array}{l}\text { Audiovestibular tests } \\
\text { imaging }\end{array}$} & \multirow[b]{2}{*}{ Diagnosis } \\
\hline No & Sex & Age & & +ve Manoeuvre & Torsion component & $\begin{array}{l}\text { Latency, } \\
\text { habit }\end{array}$ & & \\
\hline 1 & M & 47 & Positional vertigo (migraine) & $\begin{array}{l}R+L D-H \\
\text { Sagittal }\end{array}$ & R shoulder & $\begin{array}{l}\text { Latency + } \\
\text { habit }\end{array}$ & $\begin{array}{l}\text { R CP (16\%) } \\
\text { R mild SNHL } \\
\text { Normal CT }\end{array}$ & $\begin{array}{l}\text { R AC BPPV } \\
\text { FU: remitting } \\
\text { Recurrent }\end{array}$ \\
\hline 2 & M & 46 & Positional vertigo & Sagittal only & R shoulder on VOG & $\begin{array}{l}\text { Latency + } \\
\text { habit }\end{array}$ & $\begin{array}{l}\text { Normal Audiovestibular } \\
\text { tests }\end{array}$ & R AC BPPV \\
\hline 3 & $\mathrm{~F}$ & 46 & Positional vertigo (migraine) & $R+L D-H$ & $\begin{array}{l}\text { (not detected clinically) } \\
\text { Tors +ve: direction difficult } \\
\text { to ascertain }\end{array}$ & No latency & $\begin{array}{l}\text { Normal MRI } \\
\text { Normal audiovestibular } \\
\text { tests }\end{array}$ & $\begin{array}{l}\text { FU: persisted } \\
\text { AC BPPV }\end{array}$ \\
\hline \multirow[t]{2}{*}{4} & M & 62 & Positional vertigo (head & $R+L D-H$ & $R+L$ PC BPPV followed by & $\begin{array}{l}\text { No full habit } \\
\text { Latency + }\end{array}$ & $\begin{array}{l}\text { Normal MRI } \\
\text { Bilateral high frequency }\end{array}$ & $\begin{array}{l}\text { FU: normal } \\
R+L \text { PC BPPV }\end{array}$ \\
\hline & & & trauma) & & pDBN & habit & $\begin{array}{l}\text { SNHL } \\
\text { Normal vestibular tests } \\
\text { Normal MRI }\end{array}$ & $\begin{array}{l}\text { (plus pDBN) } \\
\text { FU: R PC BPPV }\end{array}$ \\
\hline \multirow[t]{2}{*}{5} & $\mathrm{~F}$ & 35 & Positional vertigo(PC BPPV) & $\begin{array}{l}R, L, R+L P C \text { BPPV } \\
\text { torsional componen }\end{array}$ & $\begin{array}{l}\text { or pDBN (without obvious } \\
\text { nt) }\end{array}$ & $\begin{array}{l}\text { Latency } \\
\text { variable }\end{array}$ & R CP $(12 \%)$ & AC/PC BPPV \\
\hline & & & & & & Habit & $\begin{array}{l}\text { Normal audio tests } \\
\text { Normal MRI }\end{array}$ & FU: recurrent \\
\hline 6 & $\mathrm{~F}$ & 68 & $\begin{array}{l}\text { Positional vertigo, space } \\
\text { phobia (myopathy) }\end{array}$ & $R+L D-H$ & $\begin{array}{l}\text { Not with pDBN but on one } \\
\text { occasion: } R \\
\text { horizontotorsional }\end{array}$ & $\begin{array}{l}\text { Latency + } \\
\text { habit }\end{array}$ & $\begin{array}{l}\text { Normal audiovestibular } \\
\text { tests } \\
\text { MRI: involutional }\end{array}$ & $\begin{array}{l}\text { AC BPPV } \\
\text { FU: persisted }\end{array}$ \\
\hline \multirow[t]{2}{*}{7} & W & 44 & $\begin{array}{l}\text { Spontaneous? and positional } \\
\text { vertigo }\end{array}$ & Sagittal only & Not observed & Latency & $\begin{array}{l}\text { Normal audiovestibular } \\
\text { tests }\end{array}$ & AC BPPV \\
\hline & & & & & & No habit & Normal MRI & $\begin{array}{l}\text { FU: better } \\
\text { subjectively }\end{array}$ \\
\hline 8 & M & 33 & $\begin{array}{l}\text { Positional vertigo (L ear } \\
\text { surgery) }\end{array}$ & $R+L D-H$ & Not observed & $\begin{array}{l}\text { No latency } \\
\text { Habit not } \\
\text { tested }\end{array}$ & $\begin{array}{l}\mathrm{L} \text { conductive } \mathrm{HL} \\
\text { MRI abnormal middle ear }\end{array}$ & $\begin{array}{l}\text { L AC BPPV } \\
\text { FU: unchanged }\end{array}$ \\
\hline 9 & $M$ & 34 & $\begin{array}{l}\text { Spontaneous and movement } \\
\text { induced vertigo (migraine } \\
\text { and L ear surgery) }\end{array}$ & LD-H & $\begin{array}{l}\text { Horizontal L oblique } \\
\text { component }\end{array}$ & $\begin{array}{l}\text { No latency } \\
\text { Habit not } \\
\text { tested }\end{array}$ & $\begin{array}{l}\mathrm{L} \text { conductive } \mathrm{HL} \\
\mathrm{CT} \text { inflammatory petrous } \\
\text { bone changes }\end{array}$ & $\begin{array}{l}\text { AC BPPV } \\
\text { ?Vestibular } \\
\text { migraine } \\
\text { FU: improvement }\end{array}$ \\
\hline 10 & $\mathrm{~F}$ & 78 & Positional vertigo & $\begin{array}{l}\text { L D-H (R D-H: eye } \\
\text { closure due to } \\
\text { vertigo) }\end{array}$ & Not observed & $\begin{array}{l}\text { Latency? } \\
\text { Habit }\end{array}$ & $\begin{array}{l}\text { Bilat High Frequency SNHL } \\
\text { Normal vestibular tests } \\
\text { Normal CT }\end{array}$ & $\begin{array}{l}\text { AC BPPV } \\
\text { FU: R PC BPPV }\end{array}$ \\
\hline 11 & $\mathrm{~F}$ & 53 & $\begin{array}{l}\text { Positional and spontaneous } \\
\text { vertigo (migraine) }\end{array}$ & $\mathrm{R}+\mathrm{L} D-\mathrm{H}$ & Not observed & $\begin{array}{l}\text { No latency } \\
\text { Partial habit }\end{array}$ & $\begin{array}{l}\text { Micro DBN (fundus) } \\
\text { Normal Audiovestibular } \\
\text { tests } \\
\text { Normal MRI }\end{array}$ & $\begin{array}{l}\text { AC BPPV } \\
\text { Vestibular } \\
\text { migraine } \\
\text { FU: fluctuating }\end{array}$ \\
\hline \multirow[t]{2}{*}{12} & $\mathrm{~F}$ & 52 & $\begin{array}{l}\text { Spontaneous vertigo+ visual } \\
\text { disorder (migraine) }\end{array}$ & $R+L D-H$ & Not observed & No latency & $\begin{array}{l}\text { Normal audiovestibular } \\
\text { tests }\end{array}$ & AC BPPV \\
\hline & & & & & & $\begin{array}{l}\text { Habit not } \\
\text { tested }\end{array}$ & Normal CT & $\begin{array}{l}\text { Vestibular } \\
\text { migraine } \\
\text { No FU }\end{array}$ \\
\hline
\end{tabular}

range 17 to 75 years old) and those with no evidence of CNS abnormality on clinical, oculographic, or imaging investigations ( 12 patients; mean age 50 , range 33 to 78 years old (idiopathic group)).

\section{CNS group}

Patients with CNS lesions had multiple system atrophy $(n=13)$, various types of cerebellar degeneration $(n=12)$, or miscellaneous disorders $(n=13)$, including cerebrovascular disease $(n=5)$, multiple sclerosis $(n=2)$, hydrocephalus $(n=2$; one idiopathic and one secondary to a high midbrain tumour). They reported walking difficulties $(n=34)$, falls $(n=15)$, slurred speech $(n=24)$ orthostatic intolerance $(n=13)$, and urinary dysfunction $(\mathrm{n}=14)$ in various combinations. Cerebellar abnormalities $(\mathrm{n}=28)$ prevailed in the neurological and oculomotor examinations, followed by autonomic $(n=11)$, pyramidal $(n=8)$, and extrapyramidal system $(n=7)$ findings. The pDBN was triggered by the Dix-Hallpike manoeuvre in 37 out of 38 patients; in one patient only the straight head-hanging manoeuvre was performed. The Dix-Hallpike manoeuvre was bilaterally positive in 35 patients and unilaterally in two. The direction of the nystagmus was usually purely down beat $(n=30)$, or associated with a horizontal $(\mathrm{n}=7)$ or torsional component $(\mathrm{n}=1)$. The onset was immediate-that is, no latency $(n=37)$. The nystagmus usually adapted-that is, positioning rather than positional nystagmus $(n=35)$. It was usually short lived $(<10 \mathrm{~s})$, particularly in degenerative conditions, but was more sustained in three patients. On sitting upright, there was no nystagmus or, occasionally, a transient up beat nystagmus was seen $(n=7)$. Habituation, tested in five patients, was negative (the nystagmus did not diminish on repeated positional testing). There was no significant vertigo during the pDBN, except in two patients with hydrocephalus.

\section{Idiopathic group}

The individual clinical data are shown in table 1. The presenting symptom was positional vertigo $(n=12)$ but four patients also reported spontaneous dizziness/vertigo. Five patients had a history of migraine, two a history of middle ear surgery, and one a myopathic syndrome of unknown cause. One patient had a history of recurrent posterior canal benign paroxysmal positional vertigo (BPPV), in another, the positional vertigo started after head trauma. No patient was on medication with CNS or oculomotor effects. The CNS and oculomotor examinations were normal. All patients had MRI $(n=8)$ or CT 


\section{A Right Hallpike}

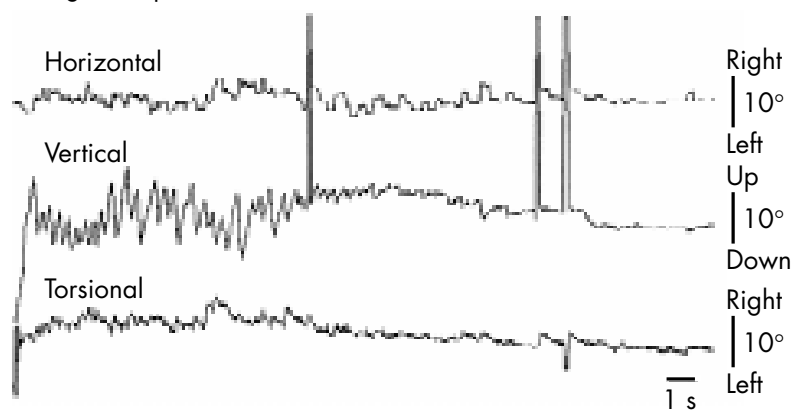

B Left Hallpike

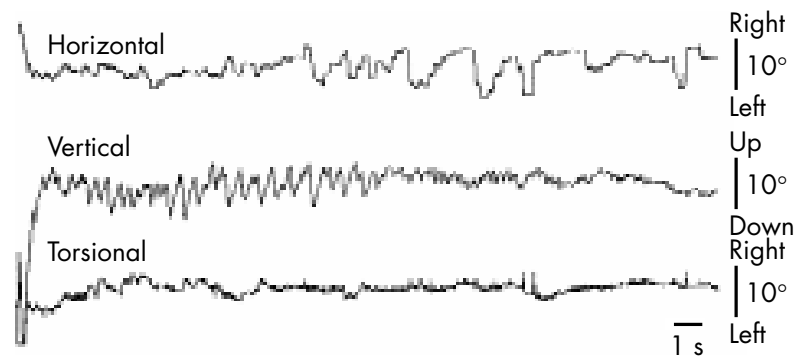

Figure 1 Three dimensional video-oculographic recordings in patient 1 with suspected anterior canal BPPV. The recordings show eye movements after the right and left Dix-Hallpike manoeuvres. The DBN predominates but a clear right beating torsional component (upper pole of the eye beating to the right shoulder) is seen both with right and left positional manoeuvres.

$(\mathrm{n}=4)$, which showed no brain abnormality. In two patients, imaging disclosed abnormalities of possible relevance in the middle ear; one a previous mastoidectomy with remaining inflammatory activity in the attic/antrum region, the other repeated middle ear surgery with remaining fluid within the left mastoid air cells and middle ear cavity.

The nystagmus was triggered by the Dix-Hallpike manoeuvre bilaterally in nine patients (75\%) and unilaterally in one. In two patients with a typical history of positional vertigo but negative Dix-Hallpike manoeuvre, the straight head-hanging manoeuvre was performed and found positive (patients 2 and 7; see case report 2 and table 1). This manoeuvre was also tried in a third patient with a positive Dix-Hallpike manoeuvre and was positive; the nystagmus during right/left Hallpike and the head-hanging position was similar (see case report 1). The nystagmus had a brief latency of 2-5 seconds in seven patients and appeared immediately in the other five. The nystagmus adapted $(<1$ minute $)$ in all patients. Habituation was investigated in nine patients and was found in seven (78\%). Most patients reported vertigo during the positional manoeuvres (11/12; not clearly stated in the notes for patient 12 ).

In six patients, torsional nystagmic components were present during the positional procedures (patients $1-6$, table 1). In two cases a unidirectional, rightwards torsional component was concurrent with the pDBN and documented by three dimensional video-oculography (see case reports 1 and 2 below). These patients were thought to have right anterior canal BPPV. In patient 1 the direction of the torsional component was the same during right and left Dix-Hallpike manoeuvre (fig 1), probably indicating bilateral triggering of the right anterior canal BPPV (fig 2). In a third patient the torsional component was also concurrent with the pDBN but the direction could not be ascertained clinically; the vertigo and nystagmus disappeared spontaneously on follow up. The most likely diagnosis was anterior canal BPPV (see case report 3). A fourth patient (patient 5), repeatedly seen over 10 years,
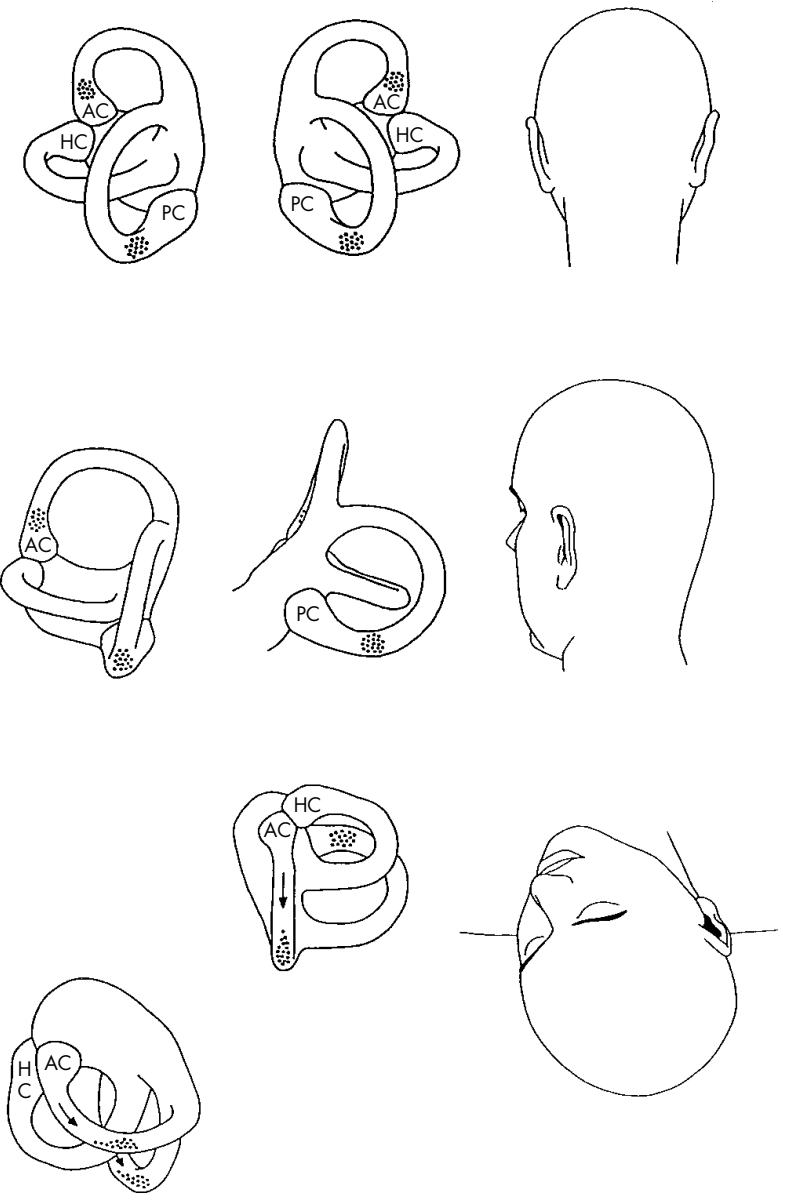

Figure 2 Top panel (head upright-straight), middle panel (head upright- $45^{\circ}$ left turn) and bottom panel (left Dix-Hallpike position) indicate the sequence of events during a left ear down Dix-Hallpike manoeuvre. Both labyrinths are viewed from behind the patient and debris have been drawn in the lumen of the anterior and posterior, but not horizontal, canals (AC, PC, HC). Note how a left

Dix-Hallpike manoeuvre is capable of inducing left and right anterior canal BPPV but only left posterior canal BPPV. The drawings were obtained by constructing in MATLAB a simple toroidal representation of the semicircular canals, based on published data for canal plane orientations $s^{47}$ and the relative positions ${ }^{47}$ and radii of curvature ${ }^{44}$ of each canal. This mathematical model was rotated $45^{\circ}$ to the left, then $120^{\circ}$ backwards, to represent the steps in the positioning manoeuvre. The drawings were made from a physical model of the bony labyrinth (SOMSO, Germany), oriented to match a back view of the mathematical model at each step.

had typical posterior canal BPPV, either on the right or left or sometimes bilateral. In some visits there was only pDBN and no torsional component was clinically noted. Despite the apparent absence of a torsional component during the pDBN (see discussion) this patient's most likely diagnosis was anterior and posterior canal BPPV. Patient 6 could show either a moderate right beating horizonto-torsional nystagmus or violent, transient pDBN with full habituation in which a torsional component was not noted; the second was thought to be anterior canal BPPV. In the remaining case (patient 4) the torsional nystagmus preceded the pDBN-that is, typical posterior canal BPPV followed by down beat while still in the Dix-Hallpike position. The main diagnosis was posterior canal BPPV; such reversal to a DBN has been previously reported in posterior canal BPPV and could be a rebound due to central adaptation..$^{14}$

In six patients no torsional component was seen during positioning (patients 7-12, table 1 ). This group comprised a patient with pDBN only provoked by the head-hanging 
manoeuvre (patient 7), two patients with unilateral middle ear disease (patients 8 and 9), a patient with typical posterior canal BPPV on follow up (patient 10), and two patients with vestibular migraine (patients 11 and 12). The presence of predisposing factors for peripheral vestibular disease and absence of CNS signs, added to the fact that a torsional component can be missed clinically (see case report 2 and discussion), suggested a labyrinthine aetiology. The more likely explanation for the pDBN in these patients was anterior canal BPPV.

Caloric testing was performed in 10 out of 12 patients; two patients had abnormal otoscopy precluding this test. Horizontal rotational responses were obtained in all patients. Combined rotational and caloric results were normal in eight patients. A mild canal paresis (12 and $16 \%$ ) in the light was present in two patients (upper normal limit 9\%). ${ }^{12}{ }^{13}$ Pure tone audiograms showed a bilateral sensorineural hearing loss in two, a unilateral sensorineural hearing loss in one (associated with canal paresis, see case 1 below), a conductive hearing loss in the two patients with clinical/imaging evidence of middle ear disease, and was normal in the remaining seven patients.

Four patients were re-examined to record the pDBN with three dimensional video-oculography but only succeeded in two (case report 1 and 2). In patient 5 we could not elicit nystagmus on the day and in patient 3 the pDBN had resolved (case report 3).

The following three case histories illustrate representative patients.

\section{Patient 1}

A 47 year old man complained of 4 years of brief positional vertigo on lying down, rising from bed, looking up, or bending forwards. He had a history of migraine. His CNS and eye movement examinations were normal. Brain CT was normal but MRI could not be obtained because of the patient's obesity. A right canal paresis of $16 \%$ in the light and a mild right low-middle frequency sensorineural hearing loss were found. Brain stem auditory evoked potentials, electro-oculography, and rotatory responses were normal.

The right Dix-Hallpike manoeuvre triggered positional vertigo and 2-3 torsional nystagmic beats to the right (upper pole of the eye beating to the right shoulder). With the left ear down, there was DBN with a latency of $2-3$ seconds, duration of 10-15 seconds, and habituation on repeated testing; no torsional component was noted. He was prescribed self paced exercises $^{16}{ }^{17}$ and 3 months later we could not elicit positional nystagmus. After a further 3 months an identical positional nystagmus was found and he was treated twice with a left Epley manoeuvre. When reviewed 3 months later the right Dix-Hallpike test showed a predominant pDBN with a small right beating torsional component. The left Dix-Hallpike manoeuvre produced only some pDBN. He was treated with a right Epley manoeuvre twice but 3 months later there was no change in the nystagmus.

He was seen 16 months later with essentially the same positional nystagmus and vertigo but both habituated on repeated testing. Video-oculography showed that during both right and left Dix-Hallpike manoeuvre the nystagmus was down-beating with a right torsional component (fig 1).The straight head-hanging manoeuvre also elicited a similar nystagmus. Slow positioning did not provoke vertigo or nystagmus in any position. Horizontal canal manoeuvres were negative.

The pDBN with a right beating torsional component was compatible with a right anterior canal BPPV. The hearing loss, normal brain stem auditory evoked potentials, and canal paresis suggested labyrinthine involvement on that side. The patient attended the laboratory weekly, four times, for treatment with the three dimensional rotator (SEGA R360) which we used successfully for treatment of posterior canal BPPV. ${ }^{18}$ We performed $360^{\circ}$ and $450^{\circ}$ forwards rotations, at $90^{\circ} / \mathrm{s}$, with the head straight and turned $40^{\circ}$ to the left or right to bring the anterior canal in the plane of rotation. These manoeuvres were carried out three times each. On stopping from the first rotation only, intense, brief DBN and vertigo was provoked; on repetition there was no nystagmus or vertigo. On weekly follow up, the Dix-Hallpike manoeuvre on the right was negative on two occasions but then became bilaterally positive again. The patient was subjectively moderately improved throughout but this was largely the result of avoiding the offending head positions.

\section{Patient 2}

A 46 year old man complained of 8 years of brief positional vertigo mainly on lying down, rising from bed, or looking up. He had experienced in the last 3 years some 10 episodes of dizziness lasting between 10 minutes to 2 hours. He had tension headaches but not migraine. Neurological and eye movement examinations were normal. Brain CT, MRI, caloric/ rotatory responses, and a pure tone audiogram were normal.

The Dix-Hallpike manoeuvre was negative but the straight head-hanging manoeuvre triggered a violent but brief $(<10 \mathrm{~s})$ pDBN. The nystagmus had a latency of a few seconds, showing habituation. This pDBN was a persistent, isolated finding in the three occasions the patient was seen between 1992 and 1999. Video-oculography showed that the pDBN was intense during the first few seconds, with slow phase velocity of $87-108^{\circ} /$, decaying rapidly to a stop after 10 seconds. A right beating torsional nystagmic component, undetected clinically but clearly visible on the analogue videotapes and oculographic traces, was documented. The slow phase velocity of the torsional component was about $30 \%$ of that of the vertical component. These findings were compatible with right anterior canal BPPV. Forward rotations with the head straight and turned $40^{\circ}$ to either side in the three dimensional rotator were performed on his last visit but in a postal reply the patient reported no significant change.

\section{Patient 3}

A 46 year old woman with a history of migraine complained of some 20 episodes of recurrent vertigo which lasted 2 or 3 days in the period 1987 to 1993. It was not clear if the vertigo was spontaneous or positional. Neuro-otological examination in 1990 was normal but for the Dix-Hallpike manoeuvre, both right and left, which triggered a pDBN. The nystagmus was intense and brief and habituated partly. There was a small associated torsional component, the direction of which could not be clearly ascertained. Caloric/rotatory responses, pure tone audiometry, brainstem auditory evoked responses, and MRI were normal. The findings were compatible with anterior canal BPPV. The patient was reassessed in 1998 as part of this study. She had no vertigo nor other symptoms between 1993-98 apart from a Bell's palsy which spontaneously recovered. Examination, including all positional manoeuvres, was negative.

\section{DISCUSSION}

Several series of patients with DBN in the upright position have been published ${ }^{1-5}$ but, to our knowledge, no series of patients with pDBN have appeared in the literature. In our 50 patients with $\mathrm{pDBN}, 75 \%$ had CNS disorders involving the cerebellum or brain stem but $25 \%$ had no evidence of a CNS abnormality,

\section{pDBN in CNS disease}

because pDBN is known to occur in CNS disease, particularly posterior fossa lesions ${ }^{19-22}$ we will only concentrate on two new points of clinical relevance. Firstly, it is important to note that no patient in our series had an Arnold-Chiari malformation, one of the most common causes of spontaneous, constant DBN. ${ }^{2-4}$ The reason for this discrepancy is not clear but it may 
indicate that the cerebellar flocculus-a site involved in the Arnold-Chiari malformation and proved to cause constant DBN in animal lesion studies ${ }^{23}$-is not the site responsible for transient pDBN. Floccular lesions in monkeys can produce positional nystagmus but this is horizontal-rotatory. ${ }^{24}$ By contrast, nodular lesions in cats ${ }^{25}$ selectively cause transient $\mathrm{pDBN}$ of the type seen in our patients with damage to the CNS.

The second point of clinical relevance is the finding of pDBN in patients with multiple system atrophy, so far only reported previously in abstract form. ${ }^{26}$ Multiple system atrophy has three main presentation types, one with atypical parkinsonism (striatonigral type), one mostly cerebellar (olivopontocerebellar type), and one with mainly autonomic nervous system features (Shy-Drager type) ${ }^{27-29}$ Most of our patients with multiple system atrophy had overt cerebellar signs but five had a prominent extrapyramidal syndrome. Thus, the positional manoeuvre is of value in the differential diagnosis of the atypical parkinsonian syndrome. The presence of pDBN is likely to depend on the presence of prominent cerebellar pathology in multiple system atrophy but not in other parkinsonian syndromes. ${ }^{29} 30$

\section{pDBN without clinical evidence of CNS disease}

The pDBN in our two groups of patients had different characteristics. In the CNS group the trend was that there was no latency or habituation of the nystagmus or significant vertigo during positioning. In the group with no evidence of CNS disease the pDBN tended to have opposite characteristics, usually accepted as due to labyrinthine disease. ${ }^{6}$ Further, in four patients who were repeatedly examined, the pDBN resolved spontaneously in one and there were no additional findings in the other three followed up for 4 to 10 years.

It is possible that these patients had a peripheral abnormality involving the anterior canal, similar to that causing BPPV. Currently, it is accepted that BPPV of the posterior and horizontal canals is due to semicircular canalithiasis - that is, freely moving debris within the endolymph. ${ }^{31}$ The nystagmus in canalithiasis is thought to be induced by the plunger effect of debris when a canal is rotated with respect to gravity and the debris sink downwards along the canal. Due to the roughly coplanar orientation of the vertical canals (left anterior with right posterior and vice versa), a left Dix-Hallpike manoeuvre for the left posterior canal rotates the right anterior canal backwards. In doing so, any debris lying on the ampullar region would travel ampulofugally on reaching the head dependent position, thus exciting anterior canal afferents ${ }^{32}{ }^{33}$ (fig 2). In turn, this should lead to pDBN with a torsional component beating towards the uppermost ear, ${ }^{34}{ }^{35}$ in this example to the right.

There have been occasional reports of suspected anterior canal BPPV but these are not always concordant. During particle repositioning treatment of posterior canal BPPV, transient pDBN has been found and attributed to invasion of the anterior canal by the canalicular debris. ${ }^{18}{ }^{36}$ The nystagmus has been reported as purely down beating ${ }^{18}{ }^{36}$ or associated with a torsional component. ${ }^{3637}$ The Dix-Hallpike manoeuvre has been reported to trigger the nystagmus on the same side ${ }^{36}$ or on the opposite side ${ }^{187}$ of the suspected anterior canal. In none of these patients, however, was the nystagmus recorded. The three dimensional oculographic trace in figure 1 combines, as expected for right anterior canal BPPV, pDBN with a torsional right beating component.

However, several features in our patients deserve discussion: (1) the rarity of anterior versus posterior canal BPPV, (2) the fact that the nystagmus was elicited bilaterally with the Dix-Hallpike manoeuvre in nine of 12 patients, (3) only triggered by the head-hanging manoeuvre in two further patients, and (4) the apparent lack of torsional nystagmic components in some patients.

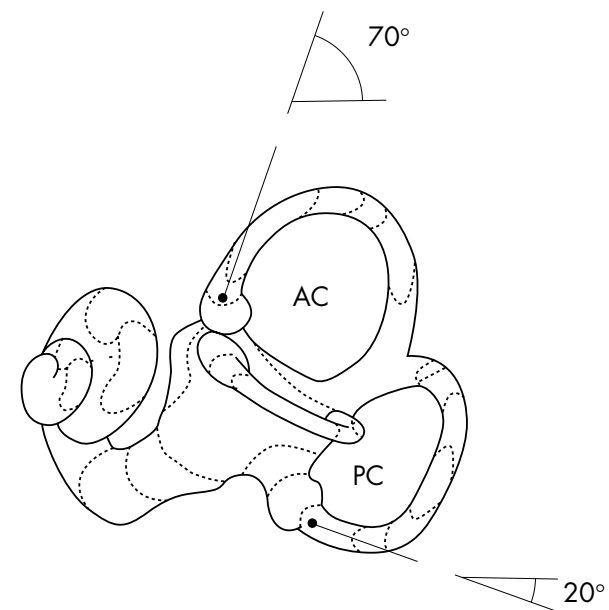

Figure 3 Schematic reconstruction of a left labyrinth based on in vitro CT scan data ${ }^{44}$ The labyrinth is viewed sideways and has been rotated backwards in pitch so that the horizontal canal lies at an angle of $30^{\circ}$ with respect to earth horizontal - that is, the position found with the head normally upright. Straight lines running through the initial portion of the ampullary segment of the anterior $(\mathrm{AC})$ and posterior (PC) semicircular canal have been added to show their respective angles with respect to earth horizontal.

\section{Rarity of anterior canal BPPV}

The rarity of anterior canal BPPV is assumed to be due to the posterior arm of the anterior canal descending directly into the common crus and vestibule. Thus, debris within the anterior canal should be self clearing. It is possible that the persistent pDBN in some of our patients represents the small proportion in whom there is difficulty clearing the anterior canal; this is also found in about $10 \%$ of patients with BPPV involving the posterior canal. ${ }^{38}$ Why this happens is unknown but could be due to the conglomerate of debris being too large, continuous production of debris, failure of disaggregation, or a narrow common crus. The failure of the whole body rotational treatment in patients $\mathrm{l}$ and 2 could also be explained by these mechanisms. Cupulolithiasis, in which debris become fixed to the cupula rather than floating freely in the endolymph, is also a cause of refractory $\mathrm{BPPV}^{39}{ }^{40}$; the almost vertical orientation of the ampullary segment of the anterior canal could result in extensive contact between debris and the cupula, thus facilitating cupulolithiasis. ${ }^{33}$ This possibility is, however, unlikely to explain our data as cupulolithiasis should not show adaptation and habituation. ${ }^{41-43}$ For these reasons the underlying mechanism of persistent positional vertigo in our patients is more likely to be refractory canalithiasis.

\section{Bilaterally positive Dix-Hallpike manoeuvre in unilateral anterior canal BPPV}

Posterior canal BBPV is usually unilateral, ${ }^{37}$ by contrast with our findings where the positional nystagmus was triggered bilaterally. There are, however, some important anatomical differences between the anterior and posterior canals which may explain why a bilateral Dix-Hallpike manoeuvre may trigger a unilateral anterior canal BPPV (figs 2 and 3).

In canalithiasis of both the anterior or posterior canal, the canaliths will collect in the ampullary segment of the respective canal with the head in the upright position (fig 2, top). On tipping the head back, the downward motion of the canaliths induces ampullo-fugal endolymph flow which stimulates the respective ampullae. However, the orientation of the ampullary segment of the anterior and posterior canal differ (fig 3, taken from in vitro CT data). ${ }^{44}$ The initial ampullary segment of the anterior canal in the upright position of the head is roughly vertical $\left(70^{\circ}\right.$ with respect to earth horizontal) whereas 
for the posterior canal it is roughly $20^{\circ}$ below horizontal. In the case of the posterior canal a head back tilt of $120^{\circ}$ in the plane of the canal takes the ampullary segment past vertical, inverting it ( $50^{\circ}$ off vertical); this will cause downward motion of the debris (fig 2, bottom). By contrast, the ampullary arm of the contralateral posterior canal remains roughly horizontal (fig 2, bottom). Thus for right posterior canal BPPV a left DixHallpike manoeuvre is not capable of provoking nystagmus because it does not orient the ampullary segment of the right posterior canal downwards.

The situation is different for anterior canal BPPV and as an example we consider right anterior canal BPPV. A left ear down Dix-Hallpike manoeuvre results in the cupula of the right anterior canal becoming superior, with the open end of the ampullary segment pointing downwards at an angle of about $40^{\circ}$ off vertical. Note that, due to the almost vertical orientation of the ampullary segment of the anterior canal, an ipsilesional left Dix-Hallpike will also attain a position whereby this segment points downwards at about $40^{\circ}$ off vertical (fig 2 bottom). The only difference in the trajectory of the two movements is that during a contralateral Dix-Hallpike manoeuvre the head rotates in the plane of the affected anterior canal whereas during the ipsilesional Dix-Hallpike manoeuvre the head rotates orthogonally to the plane of the canal. We suggest that this difference is unlikely to be critical for particle mobilisation. Evidence comes from the successful treatment of posterior canal BPPV with fast rotation backwards (heels over head rotation) ${ }^{15}{ }^{18}$ or forwards (Semont manoeuvre). ${ }^{45}$ Also, mastoid vibration, which does not cause endolymph flow, can trigger BPPV after a slow head reorientation. ${ }^{46}$ These findings indicate that endolymph flow is of secondary importance in particle mobilisation compared with fast head acceleration, gravity, and a suitable final head down position. A Dix-Hallpike manoeuvre on either side should therefore be able to provoke unilateral anterior canal BPPV.

\section{Apparent lack of torsional nystagmic components}

The finding that in six of 12 patients the nystagmus seemed to be purely down beat, as opposed to torsional down beating, could mean that these patients are a different group, and do not have anterior canal BPPV. In theory, a minute lesion of the nodulus ${ }^{25}$ could explain the pDBN without disrupting other eye movements and be missed on scanning. However, it can equally be argued that a small torsional nystagmic vector may not be detected clinically due to its short duration and the simultaneous large downbeat component. This was indeed the case in patient 2, where the torsional component was only detected by high magnification videoimaging, and in patient 3 , in whom the torsional component was seen but its direction not ascertained. The torsional nystagmic vector is smaller for the anterior than the posterior canal because the posterior canals are placed at $56^{\circ}$ from the sagittal plane whereas the anterior canals are at $41^{\circ} .{ }^{47}$ Calculations of angular eye velocity vectors derived from known canal geometry show the existence of an upwards bias in vertical slow phase eye velocity. ${ }^{48}$ Thus, more down beat than torsional nystagmus is expected from anterior canal BPPV and more torsional than up beat nystagmus in posterior canal BPPV.

\section{Nystagmus-provocation by the straight head-hanging manoeuvre}

In patient 1 , with pDBN and a right torsional component during both the right and left Dix-Hallpike manoeuvres (fig 1), it is easy to accept that the straight head-hanging manoeuvre will also provoke a similar nystagmus. The beat direction of the torsional component would be compatible with right anterior canal BPPV. Assuming that the other two patients with pDBN provoked only by the head-hanging manoeuvre may also have anterior canal BPPV we speculate why this manoeuvre may be more effective than that of Dix-Hallpike.
As discussed above, for triggering anterior canal BPPV, strict rotation in the canal plane is of relatively less importance than a final low head down position. The Dix-Hallpike manoeuvre does not achieve such low vertex positions as the head has been previously rotated $40^{\circ}-45^{\circ}$ horizontally. Indeed, observation shows that the head reaches a more dependent position, by about $20^{\circ}$, during the head-hanging than during the Dix-Hallpike position. This additional $20^{\circ}$ may be crucial for provoking anterior canal BPPV as only then the ampullary segment will approach a vertical down pointing position. By contrast, in posterior canal BPPV the canal moves past vertical even during conventional Dix-Hallpike manoeuvre.

\section{CONCLUSIONS}

In summary, pDBN is a valuable neurological sign often due to cerebellar disorder. It may help differentiate multiple system atrophy from other parkinsonian syndromes. Surprisingly, the Arnold-Chiari malformation does not seem to be a common aetiology. A smaller proportion of patients with pDBN do not show any evidence of CNS disease. It is possible that these patients have refractory anterior canalithiasis. The straight head-hanging manoeuvre should be performed in patients with a convincing history of positional vertigo but no nystagmus induced by posterior and horizontal canal manoeuvres. Video-oculography may be necessary for detecting the torsional nystagmic component added to the pDBN. Findings in audiovestibular tests and the presence of concurrent or successive BPPV of other canals can indirectly support the diagnosis of anterior canal BPPV.

\section{ACKNOWLEDGEMENTS}

Financial support from the EEC Improving Human Potential (IHP) Programme (Access to Research Infrastructures) is gratefully acknowledged. We are also grateful to Dr Mary Faldon for the diagrams presented in figure 2 .

\section{Authors' affiliations}

P Bertholon, CHU de Saint Etienne, Hopital Bellevue, Saint Etienne, France

A M Bronstein, K V Thilo, Academic Department of Neuro-otology, Division of Neuroscience and Psychological Medicine, Imperial College, Charing Cross Hospital, London, UK

A M Bronstein, R A Davies, P Rudge, National Hospital for Neurology and Neurosurgery, London, UK

\section{REFERENCES}

1 Cogan DG. Down beat nystagmus. Arch Ophthalmol 1968;80:757-68

2 Baloh RW, Spooner JW. Down beat nystagmus: a type of central vestibular nystagmus. Neurology 1981;31:304-10.

3 Halmagyi $M$, Rudge $P$, Gresty MA, et al. Down beating nystagmus, a review of 62 cases. Arch Neurol 1983:40:777-84.

4 Bronstein AM, Miller DH, Rudge P, et al. Down beating nystagmus: magnetic resonance imaging and neuro-otological findings. J Neurol Sci 1987:81:173-84.

5 Yee RD. Down beat nystagmus: characteristics and localizations of lesions. Trans Am Ophthalmol Soc 1989;87:984-1032.

6 Dix MR, Hallpike CS. The pathology, symptomatology and diagnosis of certain common disorders of the vestibular system. Proc R Soc Med 1952;45:341-54.

7 Fitzgerald G, Hallpike CS. Observations on the directional preponderance of caloric nystagmus resulting from cerebral lesions. Brain 1942;65: 115-37

8 Lopez L, Bronstein AM, Gresty MA, et al. Torsional nystagmus. A neuro-otological and MRI study of thirty-five cases. Brain 1992;115:1107-24

9 Stell R, Bronstein AM, Marsden CD. Vestibular-ocular abnormalities in spasmodic torticillis before and after botulinum toxin injections. J Neurol Neurosurg Psychiatry 1989;52:57-62.

10 Stell R, Bronstein AM, Gresty M, et al. Saccadic function in spasmodic torticollis. J Neurol Neurosurg Psychiatry 1990;53:496-501.

11 Stell R, Gresty M, Metcalfe T, et al. Cervico-ocular function in patients with spasmodic torticollis. J Neurol Neurosurg Psychiatry $1991 ; 54: 39-41$.

12 Francis DA, Bronstein AM, Rudge $\mathrm{P}$, et al. The site of brainstem lesions causing semicircular canal paresis: an MRI study. J Neurol Neurosurg Psychiatry 1992;55:446-9. 
13 Hallpike CS, Harrison MS, Slater E. Abnormalities of the caloric test results in certain varieties of mental disorder. Acta Otolaryngol (Stockholm) 1951;39:151-9.

14 Baloh RW, Honrubia V, Jacobson K. Benign positional vertigo: clinical and oculographic features in 240 cases. Neurology 1987; 37:371-8.

15 Furman JM, Cass SP, Briggs BC. Treatment of benign positional vertigo using heels-over-head rotation. Ann Otol Rhinol Laryngol 1998; 107: 1046-53

16 Brandt T, Daroff RB. Physical therapy for benign paroxysmal positional vertigo. Arch Otolaryngol 1980;106:484-5.

17 Todd Troost B, Patton JM. Exercise therapy for positional vertigo. Neurology 1992;42:1441-4.

18 Lempert T, Wolsley C, Davies R, et al. Three hundred sixty-degree rotation of the posterior semicircular canal for treatment of benign positional vertigo: a placebo-controlled trial. Neurology 1997:49:729-33.

19 Nylen CO. A clinical study on positional nystagmus in cases of brain tumor. Acta Otolaryngol 1931; (suppl 15):1-113.

20 Cawthorne T, Hinchcliffe R. Positional nystagmus of the central type as evidence of subtentorial metastases. Brain 1961;84:415-26.

21 Barber HO. Positional nystagmus. Otolaryngol Head Neck Surg 1984;92:649-55.

22 Kattah JC, Kolsky MP, Luessenhop AJ. Positional vertigo and the cerebellar vermis. Neurology 1984;34:527-9.

23 Zee DS, Yamazaki A, Butler PH, et al. Effects of ablation of flocculus and paraflocculus on eye movements in primate. J Neurophysiol 1981;46:878-99.

24 Takemori S, Cohen B. Loss of visual suppression of vestibular nystagmus after flocculus lesion. Brain Res 1974:72:213-24.

25 Fernandez C, Alzate R, Lindsay JR. Experimental observations on postural nystagmus. Lesions of the nodulus. Ann Otol Rhinol Laryngol 1960;69:94-114.

26 Anderson TJ, Bronstein AM, Luxon LM, et al. Oculomotor and neuro-otological function in multiple system atrophy: clinical and laboratory features. Neuroophtalmology 1996;16(suppl):269.

27 Wenning GK, Ben Shlomo Y, Magalhes M, et al. Clinical features and natural history of multiple system atrophy: an analysis of 100 cases. Brain 1994; 1 17:835-45.

28 Wenning GK, Tison F, Ben Shlomo Y, et al. Multiple system atrophy: a review of 203 pathologically proven cases. Mov Disord 1997; 12:133-47.

29 Litvan I, Goetz CG, Jankovic J, et al. What is the accuracy of the clinical diagnosis of multiple system atrophy? a clinicopathologic study. Arch Neurol 1997:54:937-44.

30 Tsuchiya K, Watabiki S, Sano M, et al. Distribution of cerebellar cortical lesions in multiple system atrophy: a topographic neuropathological study of three autopsy cases in Japan. J Neurol Sci 1998:80-5.
31 Furman JM Cass SP. Benign paroxysmal positional vertigo. N Engl」 Med 1999: 1590-6.

32 Baloh RW. Benign positional vertigo. In: Baloh RW, Halmagyi GM, eds. Disorders of the vestibular system. Oxford: Oxford University Press, 1996:328-339

33 Brandt T. Vertigo: its multisensory syndromes. London. Springer-Verlag. 1999.

34 Cohen B, Suzuki JI, Bender MB. Eye movements from semicircular canal nerve stimulation in the cat. Ann Otol 1964;73:153-69.

35 Minor LB, Solomon D, Zinreich JS, et al. Sound and/or pressure induced vertigo due to bone dehiscence of the superior semicircular canal. Arch Otolaryngol Head Neck Surg 1998;124:249-58.

36 Herdman SJ, Tusa RJ. Complications of the canalith repositioning procedure. Arch Otolaryngol Head Neck Surg 1996:122:281-6.

37 Honrubia V, Baloh RW, Harris MR, et al. Paroxysmal positional vertigo syndrome. Am J Otol 1999;20:465-70.

38 Wolf JS, Boyev KP, Manokey BJ, et al. Success of the modified Epley maneuver in treating benign paroxysmal positional vertigo. Laryngoscope 1999; 109:900-3

39 Parnes LS, McClure JA. Posterior semicircular canal occlusion for intractable benign paroxysmal positional vertigo. Ann Oto Rhinol Laryngol 1990;99:330-4

40 Steddin S, Brandt T. Horizontal canal benign paroxysmal positioning vertigo (h-BPPV): translation of canalolithiasis to cupulolithiasis. Ann Neurol 1996:40:918-22

41 Baloh RW, Yue Q, Jacobson KM, et al. Persistent direction-changing positional nystagmus: another variant of benign positional nystagmus? Neurology 1995;45:1297-301.

42 Lanska DJ, Remler B. Benign paroxysmal positioning vertigo: classic descriptions, origins of the provocative positioning technique, and conceptual developments. Neurology 1997;48:1 167-77.

43 Brandt T, Steddin S. Current view of the mechanism of benign paroxysmal positioning vertigo: cupulolithiasis or canalolithasis? J Vest Res 1993:3:373-82.

44 Spoor F, Wood B, Zonneveld F. Implications of early hominid labyrinthine morphology for evolution of human bipedal locomotion. Nature 1994;369:645-8.

45 Semont A, Freyss G, Vitte E. Curing the BPPV with a liberatory maneuver. Adv-Otorhinolaryngol. 1988;42:290-3.

46 Li JC. Mastoid oscillation: a critical factor for success in the canalith repositioning procedure. Otolaryngol Head Neck Surg $1995 ; 112: 670-5$

47 Blanks RHI, Curthoys IS, Markham CH. Planar relationships of the semicircular canals in man. Acta Otolaryngol 1975;80:185-96.

48 Böhmer A, Straumann D. Pathomechanism of mammalian downbeat nystagmus due to cerebellar lesion: simple hypothesis. Neurosci Lett 1998;250:127-30 